\title{
De feira popular a centro de tradições: a Feira de São Cristóvão como patrimônio imaterial do Brasil
}

Martha Nogueira ${ }^{1}$

\section{Resumo}

A política de registro de patrimônio imaterial, de responsabilidade do Instituto do Patrimônio Histórico e Artístico nacional (IPHAN), é ainda recente no Brasil, e os estudos voltados para essa área centram-se na análise, muitas vezes em âmbito institucional, dos instrumentos utilizados para o registro e das relações entre os agentes do Instituto e os detentores do bem cultural a ser registrado e salvaguardado. No presente trabalho, tomo a Feira de São Cristóvão no Rio de Janeiro, transformada há dez anos em Centro Municipal Luiz Gonzaga de Tradições Nordestinas, como objeto de uma reflexão acerca dos conflitos e contradições envolvidos no processo de elaboração do Inventário de referências Culturais e de registro do bem imaterial pelo IPHAN.

Partindo de uma perspectiva teórica que considera a espetacularização da cultura, sobretudo no contexto de requalificação de áreas urbanas degradadas, como ponto de partida para a análise das imbricações entre cultura e poder nas sociedades contemporâneas, e analisando os "usos" da tradição e da cultura popular por diferentes atores sociais, o artigo visa apontar caminhos para uma discussão sobre a validade das políticas de patrimonialização da cultura a partir do levantamento e análise das diferentes expectativas e interesses revelados nos discursos dos agentes envolvidos na questão (feirantes, integrantes do Comitê Pró-Registro da Feira, pesquisadores e gestores do IPHAN).

Palavras-chave: Cultura popular - tradição - patrimônio imaterial

\begin{abstract}
Intangible heritage register policies, under the responsibility of IPHAN, National Institute of Historical and Artistic Heritage, are still recent in Brazil and the studies on that area focus on the analysis of both the instruments used for registering and the relationship between the members of the Institute and the holders of the lore to be registered and safeguarded.In this work, I take "Feira de São Cristóvão" ("São Cristóvão District Fair"), in Rio de Janeiro,

\footnotetext{
${ }^{1}$ Doutoranda do Programa de Pós-Graduação em Ciências Sociais (PPCIS) da Universidade do Estado do Rio de Janeiro (UERJ) e professora de Sociologia e professora de Sociologia do Colégio Pedro II. E-mail: marthacnoguieira@hotmail.com
} 
transformed a decade ago into "Centro Municipal Luiz Gonzaga de Tradições Nordestinas", ("Luiz Gonzaga Municipal Center of Northeastern Traditions") as an object of reflection on the conflicts and contradictions present in the process of elaboration of an inventory of cultural references and the register of intangible heritage by IPHAN.

From a theoretical perspective that considers the spectacle of culture, especially in the context of rehabilitation of degraded urban areas, as a starting point for the understanding of the imbrication of culture and power in contemporary cities, as well as analyses the usages of traditions and folk heritage by different social agents, the article aims to explore the theme of heritage as cultural policy, leading to the discussion of its limits and possibilities.

Keywords: popular culture - folk tradition - urban folk tradition - intangible heritage

Recebido em: Julho, 2015

Aceito em: Dezembro, 2015

Para citar este artigo:

NOGUEIRA, Marta; "De feira popular a centro de tradições: a Feira de São Cristóvão como patrimônio imaterial do Brasil”, In: Revista Intratextos, 2015, vol 6, no1, p. 1-24. DOI: http://dx.doi.org/10.12957/intratextos.2015.17524 


\section{Introdução}

Neste artigo, apresento uma análise das transformações recentes que levaram um grupo de feirantes da maior feira nordestina fora do nordeste, A Feira de São Cristóvão, no Rio de Janeiro, a propor sua candidatura ao título de Patrimônio Imaterial do Brasil junto ao IPHAN (Instituto do Patrimônio Histórico e Artístico Nacional), bem como os desdobramentos relacionados ao processo de registro, as expectativas geradas entre os feirantes e os impactos dessa nova realidade sobre as relações entre os feirantes e as diferentes instâncias administrativas, agentes públicos e privados envolvidas no processo. Nessa análise, procurarei destacar as contradições que marcam o processo de transformação de práticas e manifestações da cultura popular em símbolos da diversidade cultural do país, na medida em que passam a ser incorporadas pelo Estado e integradas a novas dinâmicas relacionadas ao mercado turístico e cultural.

As transformações se tornaram mais evidentes a partir da intervenção da Prefeitura da cidade, que resultou na criação do Centro Luiz Gonzaga de Tradições Nordestinas em 2003, realizada em conjunto com a Cooperativa dos Feirantes e com o SEBRAE (Serviço Brasileiro de Apoio às Micro e Pequenas Empresas), que atuaram no sentido de orientar antigos feirantes e novos empreendedores sobre como transformar a cultura nordestina no grande atrativo de uma "nova feira" que deveria passar a atrair novos frequentadores. Os discursos que têm como eixo fundamental a defesa de tradições populares e da autenticidade das culturas, e sua apropriação por diferentes atores sociais, são a base da reflexão que se vai propor, na medida em que constituem o sentido de legitimação e das disputas que se estabelecem em torno da ideia de patrimônio.

\section{A construção de um objeto de pesquisa}

Desde o final dos anos 1990 venho realizando pesquisas na Feira de São Cristóvão. Segundo relatos dos próprios feirantes, que hoje já formam a segunda geração de migrantes nordestinos no Rio de Janeiro, a Feira surgiu naquele bairro ainda na década de 1940, quando aqueles que chegavam de viagem ao Rio de Janeiro, a bordo dos veículos conhecidos como "paus-de-arara", ou que ali se aglutinavam à espera de parentes, passaram a aproveitar o ponto, então batizado de "rodoviária dos paraíbas", para vender e comprar produtos típicos da região, trocá-los por bens industrializados do "sul", e também para rememorar outras manifestações culturais do nordeste como o repente, o forró e $\mathrm{o}$ cordel. 
Minha primeira experiência como pesquisadora na Feira de São Cristóvão se deu por ocasião da participação em projeto de iniciação científica orientado pela antropóloga Claudia Barcellos Rezende, durante o curso de graduação em Ciências Sociais na Universidade do Estado do Rio de Janeiro (UERJ). Naquele contexto, pude contribuir para o projeto, que tratava da relação entre amizade e hierarquia, já tomando como campo de pesquisa a Feira de São Cristóvão, então "descoberta” pelos jovens universitários que buscavam contato com manifestações culturais consideradas "de raiz", como o forró.

Frequentando a feira nordestina naquela época, me chamou atenção a aproximação inusitada entre trabalhadores de camadas pobres (porteiros de edifícios, empregadas domésticas, trabalhadores da construção civil) e estudantes de classe média ("patricinhas", "mauricinhos", "forrozeiros"²), propiciada por uma valorização da cultura popular que, para esses novos frequentadores da Feira, figurava como uma forma de distinção em relação aos amantes "acríticos" da cultura pop e da música internacional. A Feira era vista como o lugar onde o forró “de raiz" podia ser conhecido e apreciado por diferentes públicos.

Depois de concluir a graduação, tendo apresentado ao final uma monografia sobre a relação de amizade entre nordestinos e cariocas na Feira de São Cristóvão, passei a estudar, durante o curso de mestrado, um outro processo: a transformação da Feira em um Centro de Tradições: O Centro Municipal Luiz Gonzaga de Tradições Nordestinas.

Durante os anos que passou na completa informalidade, a Feira se manteve apenas pela força e resistência daqueles feirantes e artistas que, apesar de toda adversidade, retornavam todas as semanas àquele ponto para armar e desarmar suas lonas, ali permanecendo em atividade contínua do fim da tarde de sexta-feira até o domingo à noite. Não havia conforto nem tampouco segurança, mas famílias inteiras se revezavam no trabalho nas barracas e improvisavam espaços para tirar um cochilo nas horas de menor movimento, apesar do alto volume das caixas de som e do sempre grande número de frequentadores. Sobre os tabuleiros das barracas, havia uma gama quase infinita de produtos, além de pontos de troca e venda de produtos usados que incluíam brinquedos, roupas, relógios, peças de eletrodomésticos e eletrônicos em geral.

Apesar do predomínio do forró e do brega nas caixas de som em volume altíssimo, a disputar os ouvidos daqueles que circulavam entre as barracas, e da presença inequívoca dos pratos considerados típicos do Nordeste como a carne de sol, o baião de dois entre outros, já

\footnotetext{
${ }^{2}$ Categorias nativas utilizadas pelos informantes da pesquisa quando refletiam sobre as diferenças, não só de classe, mas de estilo de vida, perceptíveis no encontro entre nordestinos e cariocas na Feira. Jovens de classe média, em geral moradores da zona sul do Rio de Janeiro e estudantes universitários, "patrocinados pelos pais", naquele contexto tornavam-se forrozeiros ao descobrir os ritmos nordestinos e passavam a compor um estilo que envolve desde a forma de se vestir até a adaptação de passos de dança, demarcando diferenças ao mesmo tempo em que buscavam se aproximar dos nordestinos frequentadores da Feira.
} 
era possível perceber, naquele momento, que a Feira era mais do que um espaço devotado às "tradições nordestinas"; constituía-se antes, como um espaço de comércio e cultura populares, com a presença de artigos industrializados de diversas naturezas, consumidos por frequentadores pertencentes em sua maioria às camadas mais pobres, que ali tinham um ponto de encontro com música, lazer, alimentação e bebida a bom preço. A necessidade de complementar a renda com pequenos bicos dentro da Feira e a ausência de controle por parte do poder público, permitiram que aquele espaço fosse se transformando cotidianamente, para atender às necessidades e aos interesses de seus frequentadores, artistas e feirantes. Assim, era possível ouvir, ao mesmo tempo, forró, funk, brega e reggae, e as opções de alimentação incluíam, junto à tradicional buchada de bode, o famoso churrasquinho no palito, cachorroquente e x-tudo, lanches "típicos" de qualquer espaço de lazer popular, não só no Rio de Janeiro.

Naquele tempo não havia controle quanto ao que seria legítimo ou aceitável naquele espaço. A Feira funcionava como ponto de encontro entre os migrantes, que ali buscavam, além dos produtos típicos, ferramentas para o trabalho na construção civil, compravam roupas, consertavam relógio e tiravam foto $3 \times 4$. No entanto, quando a Prefeitura da cidade decidiu transformar a Feira em um Centro de Tradições Nordestinas, essa realidade mudou. A Feira deixou de ser um mercado popular improvisado e passou a contar com maior infraestrutura e segurança ao ser transferida para o interior do pavilhão abandonado, às margens do qual se situava. O pavilhão passou por uma grande reforma com a construção de pequenas, médias e grandes lojas (ainda chamadas de barracas) e de dois grandes palcos para shows, passando a receber, além de uma parte dos antigos feirantes, novos e antigos empresários do ramo da culinária especializada e do artesanato "típico". A homenagem à Luiz Gonzaga, mundialmente conhecido como o "Rei do Baião", era mais do que esperada, e junto a ela vieram outras, a evocar símbolos de uma cultura nordestina que reclamava o rótulo da "autenticidade", assentado na tentativa de valorização da gastronomia, música, literatura e arte tradicionais, a despeito da dinâmica diversificada de comércio e sociabilidade que tinha lugar na antiga Feira de São Cristóvão. Era o Estado se aproximando da Feira, e transformando-a em um espaço formalizado, onde os barraqueiros passavam a assumir compromissos com taxas antes inexistentes e a estarem submetidos a regras pautadas em uma outra lógica, voltada para o consumo turístico e cultural e para atração de públicos diversificados ${ }^{3}$. No contexto da criação do Centro Luiz Gonzaga de Tradições Nordestinas,

\footnotetext{
${ }^{3}$ Sobre o processo de criação do Centro Municipal Luiz Gonzaga de Tradições Nordestinas ver NOGUEIRA, Martha Carvalho. Estado, mercado e Cultura popular no Centro Luiz Gonzaga de Tradições Nordestinas, dissertação de mestrado apresentada ao Programa de Pós Graduação em Ciências Sociais da Universidade do Estado do Rio de Janeiro (PPCIS-UERJ), 2004.
} 
era possível notar que os discursos de defesa da tradição nordestina, feitos por políticos, administradores e gestores culturais, estavam atrelados a objetivos de mercado e que, particularmente a participação do SEBRAE na preparação dos feirantes para se tornarem empreendedores de uma "feira de sucesso", dava o tom daquela intervenção. Naquele contexto, a avaliação feita por agentes externos em relação ao que seria "típico" e "tradicional”, acabou resultando na exclusão de muitos que participavam da antiga feira, e na criação de oportunidades para que outros empresários, principalmente do setor de gastronomia, conseguissem espaço no novo Centro de Tradições. Diante disto, as conclusões a que cheguei acabaram apontando para uma crítica ao uso de categorias como tradição e cultura popular como legitimadoras de interesses políticos e econômicos que relegavam a segundo plano a dinâmica cultural instalada na antiga Feira, em nome de uma certa espetacularização da cultura.

Naquele ano de 2003, o prefeito Cesar Maia transformara a cidade em um grande canteiro de obras, e defendia o projeto de criação do Centro Luiz Gonzaga de Tradições Nordestinas, como uma intervenção estratégica, que figurava em um conjunto de mais outras quatro grandes obras, compondo o que então fora batizado por ele de "Polígono do Milênio". Abrangendo, além do Centro de Tradições Nordestinas, a Cidade do Samba, a Cidade da música, o Estádio Olímpico Municipal (hoje conhecido como Engenhão) e uma réplica do Museu Guggeinheim de Nova York, que por fim acabou não sendo construída, o conjunto das obras trazia em comum o fato de serem voltadas para a área da cultura, esfera privilegiada no que diz respeito a atração dos gestores urbanos e investidores privados alinhados à lógica do planejamento urbano estratégico ${ }^{4}$.

Em 2007, passados três anos da inauguração do Centro de Tradições, um grupo de feirantes começou a se organizar em torno do objetivo da conquista do registro da Feira como patrimônio imaterial do Brasil, com vistas a salvaguardar as práticas que caracterizam aquele espaço como um centro de referência da cultura nordestina, formando um Comitê Próregistro. É desse processo que trata o presente trabalho, parte do projeto que venho desenvolvendo para elaboração de minha tese de doutorado que se encontra em fase de conclusão.

Por meio da análise dos relatos de feirantes e de outros agentes ligados à Associação de Feirantes, ao Comitê Pró-registro e ao IPHAN, a pesquisa tem procurado discutir as questões que perpassam o processo de patrimonialização, considerando os pontos de vista dos diferentes atores sociais envolvidos. Os resultados obtidos até o momento nos permitem

\footnotetext{
${ }^{4}$ Para uma análise das políticas de planejamento estratégico e da ênfase dada à cultura nesse contexto ver ARANTES (2001), VAINER (2002), GAFFNEY e OLIVEIRA (2010)
} 
demonstrar também em que medida essas questões expressam conflitos que já ocorrem dentro da própria Feira, e em que medida podem ser compreendidos criticamente à luz de uma reflexão acerca da histórica e contraditória relação entre políticas públicas de cultura e manifestações culturais populares, sejam elas "tradicionais" ou não.

\section{A Feira como patrimônio cultural}

A transformação da feira popular, fundada por migrantes nordestinos que chegavam ao Rio de Janeiro em busca de trabalho e renda, em um centro municipal de cultura nordestina, trouxe novas questões para aqueles que tiveram de adapatar seu "negócio" com base nas orientações do SEBRAE quanto à necessidade de se adotar um espírito empreendedor para que a feira se tornasse um pólo de atração turística e cultural. Além das medidas que visavam a criação de um outro padrão de higiene na preparação e exposição dos alimentos e do investimento em segurança e infraestrutura, o cuidado com a seleção dos ritmos musicais que estariam presentes na programação dos dois grandes palcos passou a ter prioridade junto a uma empresa de gestão cultural, contratada pela Prefeitura para atuar, com a colaboração de alguns poucos feirantes, em nome do "resgate da tradição nordestina"5. Naquele momento formou-se também o Fórum Gonzagão de Cultura, que buscava atuar paralelamente aos novos gestores do pavilhão.

O Fórum Gonzagão de Cultura, criado em 2003 por iniciativa do então diretor de marketing da extinta cooperativa dos feirantes (COOPCAMPO), foi responsável pela proposição e desenvolvimento de uma série de projetos relacionados ao "resgate da cultura de raiz", como ele mesmo costuma dizer. A criação do Comitê Pró-registro da Feira como patrimônio imaterial pode ser entendida como um desdobramento das atividades desenvolvidas pelo Fórum Gonzagão, que já acumulara experiência na elaboração de projetos baseados na lógica da preservação e fomento às atividades tidas como autenticamente nordestinas. Esse comitê procurou o IPHAN em 2007 para propor a realização do inventário que permitiria a inscrição da Feira no Livro dos lugares, entre os bens imateriais da cultura brasileira. Um ex-diretor da associação de feirantes e atualmente membro do comitê próregistro explica como se deu esse processo:

A gente não sabia o que nós podíamos fazer pra dar continuidade à nossa raiz, pra dar uma segurança da nossa raiz, então um amigo, conversa pra lá conversa pra cá,

\footnotetext{
${ }^{5}$ Para maiores informações acerca da intervenção do SEBRAE e da atuação de outros grupos como a COOPCAMPO, cooperativa dos feirantes do Campo de São Cristóvão, na mediação dos contatos com os agentes da Prefeitura e na preparação para a inauguração do Centro Luiz Gonzaga de Tradições Nordestinas, ver NOGUEIRA (2004).
} 
falou do IPHAN, eu não conhecia. Então um belo dia nós tentamos marcar uma reunião com o IPHAN, até o encontro inicial foi com ... qual o nome... foi com Carlos Fernandes, que era responsável do IPHAN, era diretor responsável, uma pessoa fantástica, uma pessoa que não era nordestino mas abraçou a feira de corpo e alma e se dedicou a feira, o Carlos Fernandes. E nós começamos a conversar com ele e com a Mônica, a supervisora, que está com a gente até hoje, Carlos Fernandes não é mais superintendente do IPHAN, é outra pessoa, mas deu continuidade a Mônica. Aí nós começamos a conversar sobre o que fazer com a feira pra segurarmos nossa raíz, então eles falaram do registro imaterial, entendeu? Mônica conversou muito conosco e depois que nós conseguirmos registrar a feira, a cada dez anos esse registro é renovado, e esse registro só é renovado se nós continuarmos dando característica à feira, à cultura nordestina, continuar tendo a nossa comida típica, o artesanato típico do Nordeste, então isso é até uma segurança pra nós trabalharmos mais ainda pra não perder a nossa cultura de jeito nenhum.

O registro de bens imateriais pelo IPHAN ${ }^{6}$ vem ocorrendo no Brasil desde o ano 2000, com a publicação do Decreto federal $n^{0} 3.551$, e, atualmente, além da capoeira, que consta como um dos últimos registros, o ofício das Paneleiras de Goiabeiras, o Círio de Nossa Senhora de Nazaré, o modo de Fazer Viola-de-Cocho, o Jongo no Sudeste e a Feira de Caruaru são alguns dos bens transformados em patrimônio pelo Instituto.

Vale destacar que a defesa da preservação das manifestações culturais de natureza imaterial representa uma modificação, ou um alargamento, como se costuma dizer, da própria noção de patrimônio. Tal alargamento, responsável pela inclusão de bens culturais que representam a diversidade das culturas no Brasil, ao mesmo tempo em que representa um avanço no sentido da superação da lógica elitista que privilegiava sobretudo as grandes obras arquitetônicas do período colonial, se coloca também como uma resposta à "ameaça" representada pelo desenvolvimento da globalização e de sua suposta tendência à homogeneização cultural ao redor do mundo. Nesse contexto, a ênfase na questão da diversidade levou à valorização de manifestações locais de grupos que passaram a buscar no apoio das políticas públicas, a garantia da manutenção de suas práticas tradicionais ${ }^{7}$.

No âmbito internacional, esse debate se inicia sobretudo com a formulação, pela UNESCO, das Recomendações sobre Salvaguarda de Cultura Tradicional e Folclore em 1989, e tem como desdobramento institucional a publicação da Convenção para a Salvaguarda do Patrimônio Imaterial, e da Convenção sobre a Proteção da Diversidade das Expressões

\footnotetext{
${ }^{6}$ Registro é o termo utilizado para bens imateriais e equivale ao tombamento de bens materiais.

${ }^{7}$ Sobre a presença da ideia de "ameaça" de homogeneização cultural nos discursos oficiais que marcaram a política cultural no Brasil nas últimas décadas, ver GONÇALVES, José Reginaldo Santos. A Retórica da Perda: os discursos do patrimônio cultural no Brasil. Rio de Janeiro: Editora UFRJ; IPHAN, 1996.
} 
Culturais, nos anos de 2003 e 2005, respectivamente. Desde então, esses documentos passam a balizar as discussões sobre patrimônio e diversidade ao redor do mundo e são marcados por uma mudança nos termos utilizados, com a substituição das referências ao folclore pelo uso de expressões como "patrimônio cultural imaterial" e "expressões culturais tradicionais". Tais mudanças interferem diretamente nas políticas culturais desenvolvidas no Brasil, sendo o IPHAN e a UNESCO interlocutores permanentes na implementação das referidas Convenções.

No caso da Feira de São Cristóvão, o inventário começou a ser preparado em 2008, segundo publicação oficial da Associação de Feirantes, por uma "equipe de especialistas". Coube então a esta equipe, que se apresenta vinculada a uma "empresa de pesquisa cultural e artes visuais", o trabalho de definir o que compõe esse conjunto de práticas e eventos típicos. Essa empresa que realiza, além dos trabalhos de inventários para o IPHAN, "fotografia e filmagem publicitários, videobooks e photobooks para atores, fotografia de casamento, vídeos institucionais e filmes etnográficos, aplica a metodologia do INRC - Inventário Nacional de Referências Culturais, formulada pelo Departamento de Patrimônio Imaterial - DPI/IPHAN. Na página de apresentação de seu sítio na internet, a empresa afirma estar empenhada em ajudar seus clientes a "conhecerem sua própria história, valores e costumes"

Pude ter contato com o trabalho dos profissionais ligados a esta empresa pela primeira vez quando fui convidada a participar de um seminário no IPHAN voltado para a abertura de diálogo com a "comunidade acadêmica" que, representada por mim e por mais cinco pesquisadores, lá esteve a apresentar trabalhos de pesquisa relacionados à Feira durante um dia inteiro. A preparação de seminários como esse, assim como outros de caráter mais informativo, voltados para a própria comunidade detentora do bem a ser registrado, está prevista como uma das etapas do processo de registro de patrimônio imaterial e, assim como a elaboração do Inventário de Referências Culturais (INRC) e a produção de um vídeo documentário, estiveram, no caso da Feira de São Cristóvão, sob responsabilidade desta mesma empresa. Sobre a relação que se estabeleceu entre esses profissionais e os feirantes, G., membro do Comitê Pró-registro relata:

A gente sempre é muito receptivo, fica expectante, inclusive. A gente fica sempre na sinalização do IPHAN, porque é um trabalho que não depende dagente. A gente entra exatamente pra legitimar, dar respaldo ao projeto, apesar dagente ter proposto, acompanhou em certa fase, quando precisavam dagente a gente fazia reunião com os feirantes, levantava material, né, fazia isso tudo que isso já passou. O último encontro forte foi extamente o

${ }^{8} \mathrm{http}: / / \mathrm{www}$. charlotteproducoes.com/pt-br/ 
seminário, né, pra apresentar um documentário e tudo mais... acho que 20, 30 dias atrás a Mônica também nos ligou pragente fazer uma reunião com o comitê. O comitê, como te falei, tá sempre na expectativa, e esperando a sinalização do órgão, né, pra ver que passo a gente vai dar a partir de agora, então eles... a semana passada trouxeram um movimento de frevo, se não me engano, fizeram uma apresentação aqui, que é uma coisa que o IPHAN tá fazendo também, e teve um encontro aqui no ano passado com algumas pessoas técnicas de Brasília, que elas colocaram também algumas coisas, a gente colocou outras...

Nem todos os membros do Comitê se colocam com o mesmo entusiasmo diante da condução do processo pelos profissionais ligados ao IPHAN. M, que atua na direção cultural da atual gestão da associação de feirantes, pondera que existe muita demora no processo e chega a relacionar essa demora ao fato de haver "muita gente ganhando dinheiro com isso". Além disso, sua maior preocupação é com o possível retorno (material) que, segundo ele, deveria ocorrer em função do processo de registro. Mostra-se insatisfeito com a conquista de apenas "um papel para colocar na parede" e afirma já ter solicitado apoio ao pessoal do IPHAN para a realização de oficinas e de um documentário que ele mesmo queria fazer, mas infelizmente, não teve retorno positivo. Em uma das conversas que tivemos, M. Conclui suas queixas com a seguinte provocação: "Registra um filho e não dá leite, não dá comida pra ele pra você ver".

Em geral, a maior preocupação dos membros do comitê está relacionada ao que chamam de "invasão" de práticas que, segundo eles, não têm "nada a ver" com a cultura nordestina. Entre os maiores problemas citados pelos entrevistados até o momento, destaca-se a presença de ritmos como funk e reggae nas barracas da feira, além da comercialização de produtos fabricados na China, à exceção daqueles que trazem referências iconográficas aos pontos turísticos do Rio de Janeiro ou do Nordeste. Nota-se também, nesse sentido, a apropriação do discurso em defesa da tradição, principalmente pelos novos feirantes e artistas que compraram suas "lojas" depois da inauguração do Centro de tradições e hoje disputam espaço e legitimidade com outros barraqueiros ou ambulantes que comercializam produtos não típicos.

Diante dessas questões, que pude identificar a partir das conversas com os informantes da pesquisa, o que chama atenção é a forma como, tanto os membros do Comitê Pró-registro como os profissionais do IPHAN defendem a preservação da cultura nordestina na Feira recorrendo às categorias de tradição e autenticidade. Assim procedendo, revelam uma concepção do que seja cultura bastante essencializada, amparada na noção de que haveria 
hegemonia que caracterizam toda e qualquer manifestação, prática ou política cultural, são obscurecidas. Isto ocorre na medida em que não se busca discutir o porquê da presença dos produtos chineses na Feira, o porquê do funk e do culto evangélico, em favor de uma defesa incondicional de algo que recebe o título de autêntico ou tradicional ${ }^{9}$.

\title{
De cultura a "bem cultural": sobre os usos do patrimônio
}

Reconhecido representante dos Estudos Culturais na América Latina, Néstor García Canclini aborda o tema da tradição e do patrimônio cultural como um problema inerente aos processos de modernização nos países latino-americanos. Em sua perspectiva, a valorização do patrimônio cultural estaria ancorada, em parte, na ideia de que a preservação das tradições populares traria "benefícios espirituais" capazes de compensar as "catástrofes" da modernidade. No entanto, observa que

\begin{abstract}
Não apenas pelo interesse em expandir o mercado, mas também para legitimar sua hegemonia, os modernizadores precisam persuadir seus destinatários de que - ao mesmo tempo que renovam a sociedade prolongam tradições compartilhadas. Posto que pretendem abarcar todos os setores, os projetos modernos se apropriam dos bens históricos e das tradições populares. (CANCLINI, 2013: 159)
\end{abstract}

As análises de Canclini sugerem que, nesse contexto, opera-se por diversos meios, e em função dos interesses de diferentes agentes, a construção, ou melhor, a "teatralização" do popular. O autor cita três correntes que atuam nesse processo: os estudos de folclore (responsáveis por uma "invenção melancólica da tradição"), as indústrias culturais (que se utilizam dos meios massivos para o alcance da "popularidade" de seus produtos), e o populismo político (que busca formas de interação persuasiva com aqueles que chamam de "povo"). Em cada uma dessas vertentes, a contribuição de antropólogos, sociólogos, museólogos e comunicólogos, e a participação de políticos, narradores e educadores, tem se dado de diferentes formas em diferentes contextos. Destacam-se aí as perspectivas romântica e ilustrada - a primeira defendendo a ideia de pureza e autenticidade do popular associado a um caráter de resistência cultural, e a segunda tomando a cultura como medida de civilização. As apostas na possibilidade de inclusão ou cooptação dos setores populares por meio da ação

\footnotetext{
${ }^{9}$ Essa problematização do conceito de cultura, que ocorre tanto na antropologia como na sociologia da cultura e nos estudos culturais, é fundamental para a superação da visão essencialista da cultura e toma por base o pressuposto do caráter contraditório e inacabado das culturas que, antes de se apresentarem como totalidades coerentes e integradas, revelam assimetrias, fissuras, contradições internas e hibridizações.
} 
do Estado através das políticas culturais, contrastam com a crença no caráter potencialmente revolucionário da cultura popular.

A respeito da visão romântica dos folcloristas, Canclini argumenta que

No final das contas, os românticos se tornam cúmplices dos ilustrados. Ao decidir que a especificidade da cultura popular reside em sua fidelidade ao passado rural, tornam-se cegos às mudanças que a redefiniam nas sociedades industriais e urbanas. Ao atribuir-lhe uma autonomia imaginada, suprimem a possibilidade de explicar o popular pelas interações que tem com a nova cultura hegemônica. O povo é 'resgatado', mas não conhecido. (IDEM p. 210)

Sobre o populismo, Canclini argumenta que, ao mesmo tempo em que certas políticas na América Latina, desde Vargas e Perón até os populismos mais recentes, permitiram uma maior interação dos setores populares com a modernidade e suas forças hegemônicas como o próprio Estado, essa interação não ocorreu sem o recurso sistemático aos mecanismos de encenação, de teatralização do popular.

No populismo estatizante, os valores tradicionais do povo, assumidos e representados pelo Estado ou por um líder carismático, legitimam a ordem que estes últimos administram e dão aos setores populares a confiança de que participam de um sistema que os inclui e reconhece. (IDEM, p. 264)

Segundo a perspectiva do autor, os equívocos do folclorismo e do populismo no tratamento das questões relativas às culturas populares passam, em grande medida pela dificuldade de se reconhecer, para além do "recorte microssocial de suas análises comunitárias ou suburbanas", a "rede de macrodeterminações que os explicam" (p. 271). Assim procedendo, acabam por desconsiderar o fato de que os Estados e as indústrias culturais são espaços nos quais se pode travar uma luta pela hegemonia. Diante dessas tendências, Canclini observa a necessidade de se refundamentar a noção de popular, conferindo maior importância às categorias contradição e conflito e levando em conta, sobretudo, as imbricações contemporâneas entre o "popular" e o "massivo".

Em direção semelhante, o jamaicano Stuart Hall problematiza as noções de pureza e autenticidade a partir de uma perspectiva que prioriza a luta cultural sob as formas de “incorporação, distorção, resistência, negociação e recuperação". Em Notas para a desconstrução do popular, por meio da ênfase no caráter contraditório e inacabado da cultura popular, critica também as iniciativas de se inventariar o popular, argumentando que, em 
geral, tais iniciativas pecam por situar a cultura fora do campo das relações de dominação cultural que, antes de serem externas a ela, constituem um de seus principais elementos. Em sua perspectiva:

O que importa não é o mero inventário descritivo - que pode ter o efeito negativo de congelar a cultura popular em um molde descritivo atemporal, mas as relações de poder que constantemente pontuam e dividem o domínio da cultura em suas categorias preferenciais e residuais. (HALL, 2009:240-1)

Diante dessas considerações teóricas, convém recolocar a discussão sobre as políticas de patrimônio como forma de elucidar o debate sobre o processo de registro da feira de São Cristóvão, tanto por meio da desconstrução dos discursos pautados na defesa da tradição e da autenticidade, como por meio da análise de sua interação com o conjunto das questões macrossociológicas que envolvem os diferentes usos da cultura e do patrimônio no mundo contemporâneo.

\section{A agenda contemporânea do patrimônio}

Antônio Arantes fala sobre a "agenda contemporânea do patrimônio", destacando sua tendência à hipervalorização do aspecto estético do bem conservado em detrimento de seus usos públicos. Ao defender a relevância contemporânea das políticas de patrimônio, o sociólogo demonstra preocupação com a necessidade de se estabelecer um equilíbrio entre sua utilidade enquanto recurso econômico, que favorece a realização de "negócios", e seu aspecto dinamizador de uma cultura pública, por meio do fortalecimento dos vínculos entre lugares, usos e populações. Nesta perspectiva, não se trata de negar o caráter de construção de sentidos, inerente à noção de patrimônio, mas sim de procurar compreender como se dá essa construção, com objetivo de propor a criação de mecanismos que garantam cada vez mais a integração das minorias e das diferenças, com base em uma concepção de identidade intercultural que reflita a pluralidade existente na sociedade.

O sociólogo português Paulo Peixoto defende essa mudança de perspectiva que descreve como sendo uma evolução, a ser experimentada nas políticas de gestão cultural, das lógicas da conservação e da preservação, para lógicas de participação. Ao apresentar o resultado de seus estudos sobre os projetos de requalificação urbana em Portugal por meio da patrimonialização de centros históricos e de linhas férreas, Peixoto realiza uma crítica contundente às políticas de patrimônio, dando ênfase ao caráter idealizador de tais intervenções que visam "resgatar", por meio da valorização da cultura e das identidades locais 
e tradicionais, sentidos e usos do espaço urbano que, de certa forma, jamais existiram. Sobre a relação entre patrimônio e identidade, Peixoto argumenta que

\begin{abstract}
$\mathrm{Na}$ estreita e ambígua relação que os une, os dois termos têm vindo a ser recodificados e exacerbados, constituindo-se como uma metalinguagem das políticas urbanas. Mais do que aquilo que aparentemente significam, e enquanto metalinguagens, património e identidade representam tudo o que é ameaçado por uma urbanização lancinante, inclusive aquilo que, muitas vezes, nunca se teve: o espaço público, a qualidade de vida, uma autoestima e uma identificação incondicionais em relação ao local de residência, a cidade à escala humana. Enquanto elementos da metalinguagem da nova sintaxe do espaço urbano, património e identidade devem ser encarados como recursos retóricos das políticas urbanas, encerrando em si muitas das ideologias que sustentam essas políticas. (PEIXOTO, 2004:184)
\end{abstract}

Peixoto apresenta um questionamento acerca do crescente interesse, nas sociedades contemporâneas, pela preservação do patrimônio cultural e histórico. Em sua análise, esse interesse aparece em resposta à realidade de crise e fragmentação social que é acompanhada por um aumento de reivindicações de participação e de afirmação identitária. Nesse contexto, a defesa do patrimônio, antes de servir para fortalecer o processo de espetacularização da cultura, deveria contribuir para a construção de políticas de inclusão das novas gerações e das minorias culturais no "vasto conceito de patrimônio". No entanto, o autor pondera que isso somente poderia se dar no momento em que a tradição revanchista do aspecto higienizador, haussmaniano, das políticas de requalificação e enobrecimento urbano, desse lugar a uma nova lógica de maior participação dos diferentes segmentos da sociedade nos processos de patrimonialização. Quando não há esse sentido de participação na construção da ideia de patrimônio (afinal quem decide o que deve ser preservado?), tais políticas podem ser entendidas como uma "metalinguagem" ou como "invenção cultural”, já que, recorrendo muitas vezes a uma construção mítica, deixam passar aspectos do cotidiano vivido em favor de uma "estilização" da cultura.

Porque, mais do que objectos ou bens, ele [o patrimônio] é representação de algo. Representa o que nos arriscamos a perder, estando esta perda subsumida em identidades reais ou imaginadas, mais ou menos modestas, mais ou menos espectaculares. Reactivados, reinventados e idealizados, os bens, as práticas e os signos que dão forma material ao património são retirados das vivências quotidianas para lhes serem devolvidos de um modo onde a encenação e a estilização são factores de indução de uma consciência identitária. A condição de afirmação desta 
consciência é o seu carácter metonímico; desde a parte que é tomada pelo todo ao invólucro que é tomado pelo conteúdo. Neste processo performativo, o passado está em permanente actualização. E o que ainda não passou, na voracidade das políticas de patrimonialização, é muitas vezes esquecido, apagado ou proscrito. (PEIXOTO, 2004)

Para os objetivos deste trabalho, para além das demandas e críticas acumuladas no âmbito de uma discussão acerca daquilo que deve ou não ser objeto de patrimonialização, convém considerar o processo histórico que, no Brasil, levou à realidade que observamos nos dias de hoje, em que um número crescente de processos de registro e tombamento chamam atenção para a centralidade da cultura nas políticas de intervenção urbana.

Analisando a evolução histórica das políticas de patrimônio no Brasil, Rogério Proença Leite observa a mudança de eixo que marca a passagem de uma ênfase na identidade nacional a uma abordagem das manifestações locais, ou de uma política de construção da nação para o foco no desenvolvimento das cidades. Nessa nova abordagem, iniciada nos anos 70 e fortalecida nas décadas seguintes, o patrimônio cultural, inclusive o imaterial, são utilizados como suportes para uma política de marketing das cidades, que investe no turismo e no consumo dos lugares e de suas tradições.

O processo de descentralização das políticas de preservação, que ocorre no Brasil a partir dos anos 1970 permitiu, nas décadas subsequentes, o aprofundamento de uma lógica de utilização econômica do patrimônio como estratégia para o desenvolvimento urbano, na medida em que deslocou o foco das políticas de preservação da "nação" para as cidades, com ênfase no desenvolvimento do turismo e na redução das desigualdades regionais. A partir dessas experiências, ganha força a discussão sobre os significados do patrimônio imaterial e sobre os critérios que devem orientar as políticas de preservação.

Analisando o processo de registro do jongo no sudeste como patrimônio imaterial do Brasil, Andrea Falcão chama atenção para o fato de que “...para diversos propósitos, o patrimônio é endossado, simultaneamente, por um aparato burocrático global (UNESCO), pela indústria do turismo internacional e pelos governos nacionais" (FALCÃO, 2009: 46). Por meio da análise minuciosa de documentos públicos, cartas, ofícios e atas de reuniões relacionadas ao processo de registro do jongo no sudeste, Falcão faz uma descrição que não pretende apontar perdas ou ganhos no processo de patrimonialização de práticas culturais, mas investigar a forma como teria se desenrolado o processo na perspectiva dos diferentes agentes envolvidos. Não deixa de apontar, no entanto, aquilo que considera como sendo os aspectos positivos e negativos de maior destaque no âmbito de tais políticas. $\mathrm{O}$ aspecto 
bens de natureza imaterial, constituindo fonte segura para pesquisadores. Por outro lado, a autora destaca a impossibilidade de interferência direta do IPHAN junto às comunidades detentoras dos bens culturais. (IDEM, p. 93)

Nesse ponto, Falcão levanta uma questão contraditória, em sua opinião "um dos aspectos mais delicados da política de patrimônio imaterial": o fato de que, apesar de ter como objeto manifestações de caráter processual, cujo foco está nas pessoas e nas relações sociais, "os instrumentos de gestão e apoio disponíveis no campo da cultura não podem ser direcionados para apoio direto aos indivíduos' (id. p. 256) No caso da Feira de São Cristóvão, essa contradição da política de patrimonialização também se faz presente uma vez que, apesar os esforços dos agentes do IPHAN no sentido de estimular o envolvimento dos feirantes com as atividades que envolvem a construção do inventário e o pedido de registro, os sentidos atribuídos pelos sujeitos à própria ideia de patrimônio são diversos e incluem, desde a conquista de um objetivo pessoal daqueles que encaram a defesa da "cultura tradicional nordestina" como missão individual, até a construção de um novo nicho de mercado (o mercado do patrimônio, que atrai turistas para o consumo de lugares e de produtos tradicionais).

Existe uma questão que é pretendida por todos que de alguma maneira estão informados sobre o processo de registro, que é a garantia do direito à manutenção do espaço do pavilhão como sede da feira nordestina (que muitas vezes sofreu ameaça de ser removida do bairro de São Cristóvão). Para além desta questão objetiva, os usos e os sentidos atribuídos ao discurso em defesa da tradição e do patrimônio cultural da Feira multiplicam-se e por vezes entram em contradição, na medida em que revelam a incompatibilidade de um discurso em defesa do popular, que se constrói dentro de um contexto de políticas impopulares, no sentido em que se baseiam na defesa do empreendedorismo, na realização de parcerias público-privadas e na ideia de cultura como mercadoria, relegando a segundo plano a construção de mecanismos eficazes de participação e a necessidade de enfrentar as tradições indesejadas que dizem respeito a uma cultura política clientelista e à escassez de recursos públicos para a cultura.

Essa preocupação é partilhada por muitos profissionais que atuam nos processos de registro de patrimônio imaterial junto ao IPHAN ou ao Centro Nacional de Folclore e Cultura Popular (CNFCP). Não por acaso, Falcão relata que, como conclusão de um seminário que reuniu diferentes equipes ligadas ao CNFCP, o coletivo reunido defendeu que o sucesso de tais políticas dependeria de sua articulação com outras políticas públicas na área social, já que, sobretudo nos segmentos populares, a possibilidade de manutenção de práticas culturais está 
diretamente ligada à possibilidade de seus detentores terem acesso a um bom sistema de saúde e de previdência social, por exemplo.

$\mathrm{Na}$ tese de Falcão, o relato minucioso das discussões internas entre pesquisadores e técnicos do IPHAN, possibilitado em parte pelo fato de ter ela própria atuado com diferentes inserções junto ao Departamento de Patrimônio imaterial e como pesquisadora do CNFCP, revela esse aspecto interessante de um campo e de uma política pública que é ainda recente no país e que conta com uma grande diversidade e intensa alternância de profissionais historiadores, antropólogos, músicos entre outros. A emergência das críticas em falas reiteradas a respeito das falhas e dos limites dos instrumentos utilizados para a realização das políticas de registro são bastante esclarecedoras nesse sentido.

Em meio a essa rica descrição, e fazendo referência às teses de Bourdieu, Falcão enfatiza o caráter ritual dos processos de patrimonialização, que ao tomarem a cultura como uma "entidade objetiva", a inserem em um universo mágico, no qual extensos e complicados ciclos de consagração de certos bens garantem a autolegitimação de tais políticas, apesar de suas inúmeras falhas e incoerências internas. Assim como a tese de Falcão, existem outros trabalhos feitos sobre processos de registro de patrimônio imaterial, que deverão ser analisados no âmbito da tese que estou desenvolvendo. Por ora, julgo importante levantar também algumas questões relativas ao histórico do desenvolvimento das políticas culturais no Brasil.

\section{Sobre as políticas culturais no Brasil e o lugar o patrimônio imaterial}

Antônio Rubim analisa as políticas culturais no Brasil considerando diferentes momentos históricos e contextos políticos: o primeiro vai de 1930 a 1945 (Estado Novo, Era Vargas); o segundo, de 1945 a 1964 (o “interregno democrático”); o terceiro tem início em 1970, com o fim da era Rodrigo de Mello Franco, que se manteve por mais de 30 anos à frente do SPHAN, órgão público de maior importância dentro da política cultural naquele período, sendo então substituído por Aloísio Magalhães; e, mais recentemente, destacam-se a guinada neoliberal promovida pelos governos de Fernando Collor de Melo, Itamar Franco e Fernando Henrique Cardoso (de 1990 a 2002), e as mudanças implementadas pela gestão de Gilberto Gil, já no governo Lula.

Em relação ao contexto do Estado Novo, na década de 1930, quando são inauguradas as primeiras experiências nesse sentido, com a implantação do Ministério da Educação e Saúde tendo à frente Gustavo Capanema (de 1934 a 45), e com a passagem de Mario de

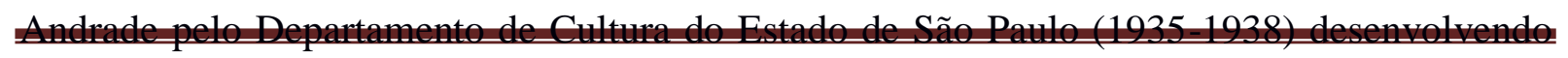


projetos que se tornaram referência para a política cultural em âmbito nacional, Rubim aponta a combinação entre a presença de um modernismo na arte, com destaque para a contribuição de Mario de Andrade, e autoritarismo na política. Institucionalmente, essa combinação de valorização da cultura e política autoritária se expressa na atuação simultânea do SPHAN (Serviço do Patrimônio Histórico e Artístico Nacional, crido em 1937), do CNC (Conselho Nacional de Cultura, de 1938) e do DIP (Departamento de Imprensa e Propaganda), que buscava, ao mesmo tempo, reprimir e cooptar o meio cultural, seus artistas e intelectuais. (RUBIM, 2007). No âmbito das políticas de patrimônio desenvolvidas pelo SPHAN, destacase desde esse período a ênfase na preservação de uma memória essencialmente branca e católica, pautada em uma estética barroca de teor monumental, e na valorização do que se convencionou chamar de "patrimônio de pedra e cal", como casarios, fortes, mosteiros, igrejas e quartéis.

O segundo momento analisado por Rubim é o período entre 1945 e 1964, o “interregno democrático", que teria garantido maior espaço para atuação de instituições não estatais como os Centros de Cultura Popular (CPC's) da UNE (1961 - 64), tendo, no entanto avançado pouco no sentido da revisão das políticas públicas na área de cultura. Destaca-se nesse período a atuação do ISEB, atuando ainda no sentido da produção de ideologias relacionadas ao ideário nacional-desenvolvimentista.

Albuquerque Jr, em artigo publicado na mesma coletânea organizada por Rubim, chama atenção para o fato de que, nesse período, percebe-se uma redução dos investimentos na área da cultura. O esvaziamento das instituições criadas na Era Vargas seria, na verdade, sintoma da emergência de uma nova política, que abre mão de gerir (para controlar) a cultura, e cria espaço para atuação de agentes privados na área da produção cultural. Após o golpe de 1964, tal conjuntura se modifica, com a retomada dos investimentos públicos na cultura. Com exceção dos momentos de maior violência e repressão, como o período de 1968 a 74, designado como uma era de "vazio cultural", a ditadura revelou mais uma vez o sentido da vinculação entre política cultural e autoritarismo estatal. Segundo Rubim, sobretudo nos anos finais, de abertura gradual do regime,

A tradição da relação entre autoritarismo político e políticas culturais é retomada em toda sua amplitude. O regime para realizar a transição sob sua hegemonia busca cooptar os profissionais da cultura (ORTIZ, 1986, p. 85), inclusive através da ampliação dos investimentos na área. Pela primeira vez o país terá um Plano Nacional de Cultura (1975) e inúmeras instituições culturais são ampliadas (MICELI, 1984), dentre elas: Fundação Nacional das Artes (1975), Centro Nacional 
de Referência Cultural (1975), Conselho nacional de Cinema (1976), RADIOBRÁS (1976), Fundação Pró-Memória (1979). (RUBIM, 2007: 21)

No contexto internacional acontece, em 1970, o I Encontro sobre Políticas Culturais promovido pela UNESCO, com reedições em 72, 73, 75, 78 e 82. As discussões ocorridas nesses encontros internacionais tornam-se, desde então, marcos decisivos na reorientação de tais políticas no Brasil e na América Latina. Em relação à política patrimonial, maior atenção passa a ser dada às manifestações populares, ao artesanato e às técnicas tradicionais, sobretudo com a atuação de Aloísio Magalhães, que retoma algumas das ideias apresentadas por Mario de Andrade ainda na década de 30, em seu projeto de reformulação das políticas do SPHAN.

De acordo com a análise de Rubim, é nesse período que se iniciam as mudanças mais significativas no campo das políticas de patrimônio no Brasil, visto que aí se inaugura uma perspectiva que já não se coloca em defesa de tradições com o propósito de civilizar o Brasil, mas adota-se um discurso voltado para a preservação da diversidade cultural. Nesse contexto, a própria noção de "patrimônio histórico e artístico" é substituída. Passa-se então a falar em "bens culturais", e a estabelecer relações entre sua preservação e a ideia de desenvolvimento.

A partir daí o que se observam é a criação de mecanismos que, embasados nos princípios neoliberais defendidos pelos governos Collor de Melo e FHC, permitiram cada vez mais a reformulação da dinâmica da produção cultural no Brasil através de sua sujeição à lógica de mercado. Collor extingue o Ministério da Cultura, a EMBRAFILME e o SPHAN e cria a Lei Rounanet e a Lei do Audiovisual, ambas visando proporcionar o incremento das atividades culturais mediante renúncia fiscal oferecida às empresas privadas, que passam a ser suas maiores patrocinadoras.

Alguns anos depois, Fernando Henrique Cardoso recria o Ministério e nomeia Francisco Weffort. Weffort é responsável pelo lançamento, em 1995, de uma publicação oficial cujo título "Cultura é um bom negócio" mostra-se bastante revelador do sentido da política que se pretendia desenvolver a partir de então, conferindo sempre maior espaço para a atuação da iniciativa privada ou, segundo uma perspectiva mais crítica, adotada por Rubim, ampliando as possibilidades de transferência de recursos públicos para o setor privado. Weffort é a pessoa que realiza essa mudança de perspectiva nas políticas culturais, substituindo a lógica da criação de uma ideologia da cultura brasileira por uma ênfase declarada no valor de mercado da cultura e de sua diversidade: 
Em outro texto, publicado na Série Cadernos do Nosso Tempo e editada pela FUNARTE (MINC), Weffort defende que o Estado deve promover a cultura, observando-a como um valor em si e como produto de mercado, pois "é impossível deixar de reconhecer a relevância do mercado no mundo da cultura, assim como da cultura na economia. (WEFFORT, 2000, p.65)" (BARBALHO, p. 51)

Com a promessa de inauguração de uma nova era na política brasileira, o Partido dos Trabalhadores chega ao poder por meio da eleição de Luiz Ignácio Lula da Silva como presidente no ano de 2002. Empossado como Ministro da Cultura, o renomado músico baiano e representante do movimento tropicalista, Gilberto Gil, declara que, em consonância com as propostas da UNESCO de valorização da diversidade cultural e do patrimônio intangível, irá trabalhar no sentido de promover a "coexistência harmoniosa das várias formas possíveis de brasilidade", incorporando as expressões culturais historicamente excluídas às políticas culturais.

Embora tenha sido notável a ampliação dos recursos públicos destinados ao setor, que tem seu orçamento triplicado em relação ao período de gestão do ministro Weffort sob o governo FHC, pode-se observar a manutenção da afinidade entre as propostas do ministro Gilberto Gil e os debates em âmbito internacional a respeito da economia da cultura e da importância do desenvolvimento da economia criativa, o que revela, em certo sentido, a permanência da lógica neoliberal que associa desenvolvimento e crescimento econômico à defesa da interferência do setor privado nas áreas sociais e culturais. Em artigo publicado no ano de 2004 e disponível atualmente no blog Cultura e Mercado editado por Leonardo Brant, Gil defende que:

\footnotetext{
$\mathrm{Na}$ era da informação, em que o saber e o simbólico tornam-se os principais ativos de uma economia, de um país, de uma empresa e de qualquer organização, grupo ou comunidade, a vitalidade e a diversidade cultural são decisivos. A cultura é um tesouro, um ativo social e econômico em permanente estado de transformação, que não pára no tempo e no espaço, e que se revitaliza no diálogo entre tradição e invenção. (GIL, 2004)
}

Em outro trecho do mesmo artigo, pode-se notar que o alargamento do conceito de cultura proposto pelo ministro Gilberto Gil abre caminhos especialmente para a incorporação desse "ativo" pelo mercado e pelo mundo dos negócios:

quando falamos de cultura, falamos da essência da vida humana. De algo tão vital quanto o ar, quanto a própria natureza. Por isso, é necessário conectar a cultura a 
todas as dimensões da existência, ao que faz o mundo funcionar, sobretudo à economia e aos negócios. (idem)

Alexandre Barbalho, em artigo intitulado Políticas Culturais no Brasil: identidade e diversidade sem diferença, também trata dessa mudança de foco nas políticas culturais, que abandonam o ideário de construção de uma identidade nacional em favor da valorização de uma multiplicidade de polos de criação e produção culturais. Em sua perspectiva, a fala em defesa da diversidade e da cultura miscigenada, dissociada de um olhar crítico para as desigualdades regionais e de classe, revela uma simples substituição do autoritarismo presente na política dos anos 30/40 e 60/70 por uma outra lógica que segue negando a existência de antagonismos inerentes ao campo social, na medida em que valoriza a aclamada diversidade apenas enquanto matéria prima para a composição de um mosaico de diferenças que podem e devem ser agrupadas ainda sob o rótulo de uma miscigenação sem contradições, ou de uma "cultura brasileira" sempre marcada pela harmonia interna, pela espontaneidade de suas manifestações plurais, sincréticas e democráticas. Barbalho critica essa descontinuidade aparente das políticas culturais no Brasil e defende que

\footnotetext{
O discurso identitário se perde no essencialismo autoritário e conservador dos anos 1930/40 e 1960/70, passa a ser pautado pela lógica do mercado globalizado. Uma vez posto em cheque o lugar unificador e integrador da identidade nacional, parece prevalecer o discurso liberal da diversidade, onde todos são iguais perante o mercado. (BARBALHO, 2007:56)
}

Nesse sentido, cabe problematizar a ênfase no avanço das políticas culturais na era Gil, tida como marco fundamental até os dias de hoje, dado seu perfeito alinhamento à lógica operada pelos organismos internacionais como a UNESCO e com as tendências contemporâneas de exaltação da economia da cultura, a despeito de sua desvinculação a um conjunto mais amplo de políticas sociais, desmontadas pela efetivação do ideário neoliberal na gestão pública.

Em relação à Feira de São Cristóvão, o que se busca compreender com essa pesquisa, é a maneira como essa política de registro está se dando, e quais as possibilidades concretas de que, por meio dela, se possam alcançar os objetivos (diversos) almejados pelos próprios feirantes. Para tanto, a análise dos usos da cultura e do patrimônio por diferentes atores sociais e sua vinculação a uma defesa estratégica das tradições populares como matéria prima para a realização de políticas públicas e de investimentos privados, parece se mostrar profícua. Afinal, diante do histórico das políticas culturais no Brasil e da própria história da inserção da 
Feira de São Cristóvão na cidade do Rio de Janeiro, cabe ainda indagar se as mudanças recentes nos discursos ligados à cultura e a ampliação do conceito de patrimônio, voltado para a inclusão de grupos diversos, será capaz de superar a tradição autoritária e folclorizante que tem sido a marca da relação do Estado com as manifestações culturais populares.

No caso da Feira de São Cristóvão, é preciso levar em conta ainda, que a construção imagético-discursiva que contribui para a reafirmação dos estereótipos ligados a ideia de cultura nordestina (ALBUQUERQUE JR, 2001), oscilando entre a exaltação da beleza de sua música, literatura e artesanato, o receio de seu caráter violento (do "cabra macho" que a qualquer momento parece ser capaz de "sacar a peixeira") e o interesse de se tirar proveito de sua cultura política, supostamente pautada nas práticas do coronelismo e do clientelismo, parecem trazer importantes elementos para essa reflexão. Afinal, para além daquilo que se quer preservar como ícones emblemáticos da cultura nordestina - o repente, o cordel, o forró, a culinária típica etc, há também outras realidades, subliminares, que insistem em se fazer presentes sob a forma de fantasmas de um passado que não se quer preservar, mas com o qual é preciso saber lidar.

\section{Referências bibliográficas}

ALBUQUERQUE Jr, Durval Muniz de. A Invenção do Nordeste e outras artes. São Paulo: Cortez, 2001.

"Gestão ou Gestação pública da Cultura: algumas reflexões sobre o papel do Estado na produção cultural contemporânea". In: RUBIM e BARBALHO (orgs.) Políticas Culturais no Brasil. Salvador: EDUFA, 2007.

ARANTES, Otilia. "Uma estratégia fatal. A cultura nas novas gestões urbanas". In: A Cidade do Pensamento Único. Petrópolis:Vozes, 2002.

ARANTES, Antônio. "Patrimônio cultural e cidade". In: FORTUNA, Carlos e LEITE, Rogério Proença. Plural de Cidade: novos léxicos urbanos. Coimbra: Almedina, 2009.

BARBALHO, Alexandre. "Políticas Culturais no Brasil: Identidade e Diversidade sem diferença". In: RUBIM e BARBALHO (orgs.) Políticas Culturais no Brasil. Salvador: EDUFA, 2007 (pp. 37-60).

CANCLINI, Néstor García. Culturas Híbridas. São Paulo: EdUSP, 2013.

CASTRO, Maria Laura Viveiros de e FONSECA, Maria Cecília Londres. Patrimônio imaterial no Brasil. Brasília: UNESCO, Educarte, 2008.

CHAUÍ, Marilena. 1986. Conformismo e Resistência: Aspectos da Cultura Popular no

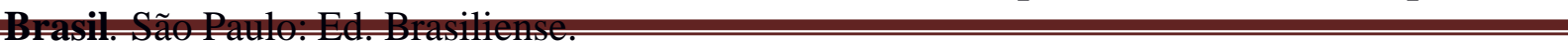


DEBORD, Guy. A Sociedade do Espetácul $o$. Rio de Janeiro: Contraponto, 1997.

FALCÃO, Andréa Rizzotto. 2011 Novas demandas, outros desafios. Estudo sobre a implementação da política do patrimônio imaterial no Brasil e seus desdobramentos no processo de inventário, registro e salvaguarda do jongo. Tese de doutorado apresentada ao Programa de Pós-graduação em Ciências Sociais da Universidade do Estado do Rio de Janeiro (PPCIS-UERJ)

FOUCAULT, Michel. Microfísica do Poder. Rio de Janeiro: Ed Graal, 1998.

GIL, Gilberto. Por uma nova arquitetura de investimento cultural. Disponível em: http://www.culturaemercado.com.br/procultura/o-investimento-cultural-privado-por-gilbertogil/)

GRAMSCI, Antonio. 2006. "Apontamentos para uma introdução e um encaminhamento ao estudo da filosofia e da história da cultura." Introdução ao estudo da filosofia. A filosofia de Benedetto Croce. Cadernos do Cárcere vol. 1. pp. 93-114. Rio de Janeiro: Civilização Brasileira.

HALL, Stuart. Identidades Culturais na Pós-modernidade. Rio de Janeiro: DP\&A Editora, 1997. Brasília: IPHAN,1998.

"Identidade Cultural e Diáspora". In: Revista do Patrimônio.

“Notas para a Desconstrução do Popular”.In: Da Diáspora, 2000.

JAMESON, Fredric. Pós-modernismo. A lógica cultural do capitalismo tardio. São Paulo: Ed Ática, 1996.

LEITE, Rogerio Proença. Contra-usos da cidade. Lugares e espaço público na experiência urbana contemporânea. Campinas, SP: Editora UNICAMP, Aracaju, SE: Editora UFS, 2007.

NOGUEIRA, Martha Carvalho. Estado, Mercado e Cultura Popular no Centro Luiz Gonzaga de Tradições Nordestinas. (Dissertação de mestrado apresentada ao programa de Pós-graduação em Ciências Sociais da Universidade do Estado do Rio de Janeiro, 2004).

PEIXOTO, Paulo. "A identidade como recurso metonímico dos processos de patrimonialização". Revista Crítica de Ciências Sociais, n 70, 2004. Disponível em: http://rccs.revues.org/1056

PEIXOTO, Paulo e LEITE, Rogerio Proença. O patrimônio como elixir de políticas urbanas: notas sobre o bairro do Recife e a zona histórica da cidade do Porto. Publicação nos anais da $26^{\mathrm{a}}$ ABA, 2008

RUBIM, Antônio Albino Canelas. "Políticas culturais no Brasil: tristes tradições enormes desafios". In: RUBIM e BARBALHO (orgs.) Políticas Culturais no Brasil. Salvador: EDUFA, 2007.

SAID, Edward. O Orientalismo. São Paulo: Companhia das Letras, 2007.

THOMPSON, E. P. Costumes em Comum. Estudos Sobre a Cultura Popular Tradicional. São Paulo: Companhia das Letras, 1998. 
WILLIAMS, Raymond. Cultura e Materialismo. São Paulo: Editora UNESP, 2011. 